\title{
Analisis Potensi Kebangkrutan dengan Metode Altman Z-Score, Springate (S-Score), Zmijewski (X-Score) \& Grover (G-Score) Pt. Hexindo Adiperkasa, Tbk Periode Tahun 2016-2019
}

\author{
Devi Romauli Br Sitanggang1', Naomi Putri Sion Silaban² \\ Program Studi Pendidikan Ekonomi, Universitas Muhammadiyah Riau \\ e-mail: deviromaulisitanggang@gmail.com
}

\begin{abstract}
Abstrak
Penelitian ini bertujuan untuk menganalisis dan mengukur nilai skor kebangkrutan dengan menggunakan model Altman Z-Score, Zmijewski, Springate, dan Grover. Sampel menggunakan PT. Hexindo Adiperkasa Tbk periode 2016-2019. Dalam melakukan penelitian ini, penulis menggunakan metode studi deskriptif dan metode studi kasus. Data yang digunakan adalah data sekunder yang diperoleh dari website resmi perusahaan. Hasil penelitian membuktikan bahwa: perhitungan Altman Z-Score, Zmijewski, Springate, dan Grover memprediksi bahwa PT. Hexindo Adiperkasa Tbk pada periode 2016-2019 dalam kondisi sehat. Penelitian ini hanya merupakan gambaran keadaan perusahaan yang tidak $100 \%$ benar. Hasil dari metode perhitungan tersebut digunakan sebagai evaluasi kedepannya agar perusahaan dapat meningkatkan kinerjanya. Penelitian ini juga dapat dijadikan sebagai ilustrasi untuk pengambilan keputusan investasi bagi investor.
\end{abstract}

Kata kunci: Financial Distress, Altman Z-Score, Zmijewski, Springate, Grover

\begin{abstract}
This study aims to analyze and measure the value of bankruptcy scores using the Altman ZScore, Zmijewski, Springate, and Grover models. Samples using PT. Hexindo Adiperkasa Tbk period 2016-2019. In conducting this research, the writer uses descriptive study method and case study method. The data used is secondary data obtained from the company's official website. The results of the study prove that: Altman Z-Score, Zmijewski, Springate, and Grover calculations predict that PT. Hexindo Adiperkasa Tbk in the 2016-2019 period is in a healthy condition. This research is only a description of the state of the company which is not $100 \%$ correct. The results of the calculation methods are used as future evaluations so that the company can improve its performance. This research can also be used as an illustration for making investment decisions for investors.
\end{abstract}

Keywords : Financial Distress, Altman Z-Score, Zmijewski, Springate, Grover

\section{PENDAHULUAN}

Laporan keuangan digunakan sebagai bentuk pertanggungjawaban kepada publik untuk memonitor kinerja dan mengevaluasi manajemen, memberikan dasar untuk mengamati tren antar kurun waktu, pencapaian atas tujuan yang telah ditetapkan dan membandingkannya dengan kinerja organisasi lain yang sejenis jika ada, serta memungkinkan pihak luar untuk memperoleh informasi biaya atas barang dan jasa yang diterima dan untuk menilai efisiensi dan efektivitas penggunaan sumber daya organisasi\#(Astuti et al., 2020; Lubis et al., 2019)\#. Laporan keuangan juga berfungsi untuk membantu perusahaan untuk memberikan dasar perencanaan kebijakan dan aktivitas di masa yang akan datang, terutama informasi pendukung penggunaan dana dan kelangsungan organisasi (viability). Setiap perusahaan didirikan dengan harapan akan menghasilkan profit sehingga mampu untuk bertahan dan berkembang dalam jangka panjang yang tak terbatas. Hal ini berarti dapat diasumsikan bahwa perusahaan akan terus hidup dan diharapkan tidak akan mengalami likuidasi. Dalam praktik, asumsi seperti di atas tidak selalu menjadi 
kenyataan. Seringkali perusahaan yang telah beroperasi dalam jangka waktu tertentu terpaksa bubar karena mengalami financial distress yang berujung pada kebangkrutan (Rismawaty, 2012).

Menurut Maria Immaculatta (2006), kualitas keputusan investor dipengaruhi oleh kualitas informasi yang diungkapkan perusahaan dalam laporan keuangan. Kualitas informasi tersebut bertujuan untuk mengurangi asimetri informasi yang timbul ketika manajer lebih mengetahui

informasi internal dan prospek perusahaan di masa mendatang dibanding pihak eksternal perusahaan. Oleh karena itu, integrasi informasi untuk menyediakan informasi relevan kepada publik akan mempengaruhi keputusan \#(Azmi et al., 2020)\#. Informasi yang berupa pemberian pemeringkatan yang dipublikasikan terhadap perusahaan yang tercatat diharapkan dapat menjadi sinyal kondisi keuangan perusahaan tertentu dan menggambarkan kemungkinan yang terjadi terkait dengan kinerja dan utang yang dimiliki oleh perusahaan tersebut.

Sehingga dapat dikatakan bahwa publikasi laporan keuangan tahunan dan publikasi data perusahaan yang dikeluarkan oleh BEI (Bursa Efek Indonesia) baik berupa rating industri maupun hasil pengolahan rasio oleh pihak BEI, dapat menunjukkan kondisi kekurangan keuangan baik secara industri ataupun masing-masing perusahaan terbuka. Informasi BEI tersebut diharapkan akan mampu memberikan sinyal bagi investor maupun calon investor mengenai kinerja perusahaan tertentu.

Menurut Kusuma (2006) pada signaling theory terdapat motivasi manajemen dalam menyajikan informasi keuangan yang diharapkan dapat memberikan sinyal kemakmuran kepada pemilik ataupun pemegang saham. Publikasi laporan keuangan tahunan yang disajikan oleh perusahaan akan dapat memberikan signal per tumbuhan dividen maupun perkembangan harga saham perusahaan.

Perusahaan manufaktur merupakan industri yang dalam kegiatannya mengandalkan modal dari investor, oleh karena itu perusahaan manufaktur harus dapat menjaga kestabilan keuangannya. Mengingat besarnya pengaruh yang timbul bila terjadi kesulitan keuangan pada industri manufaktur, maka perlu dilakukan analisis sedemikian rupa sehingga kesulitan keuangan dan kemungkinan kebangkrutan dapat dideteksi lebih awal.

Berbagai pengembangan analisis keuangan tersebut dilakukan untuk memprekdisi kondisi keuangan perusahaan. Analisis yang banyak digunakan saat ini adalah analisis model altman Z-Score dimana analisis ini mengacu pada rasio-rasio keuangan perusahaan. Rasio menggambarkan suatu hubungna atau pertimbangan (mathematical relationship) antara suatu jumlah tertentu dengan jumlah yang lain, dan dengan menggunakan alat analisis berupa rasio ini akan dapat menjelaskan atau memberi gambaran kepada penganalisis tentang baik atau buruknya keaadaan atau posisi keuangan suatu perusahaan terutama apabila angka ratio pembandingan yang digunakan sebagai standar (Munawir, 2007:64)

Selain analisis model altman Z-score, masih banyak jenis model yang telah digunakan penelitian-penelitian sebelumnya dalam memprediksi keadaan keuangan suatu perusahaan. Misalnya, model springate, model zmijewski, model grover, model fulmer, model CA-score, dan sebagainya. Dengan diketahui model-model prediksi kondisi keuangan yang tepat dan penggunaan informasi keuangan perusahaan-perusahaan terpublikasi oleh BEl, diharapkan investor maupun pihak-pihak lain yang berkepentingan dalam analisis keuangan agar dapat mengambil keputusan dengan lebih baik.

Hexindo merupakan perusahaan pengadaan alat berat yang juga dipercaya sebagai pemegang merek resmi atas alat-alat berat dan suku cadang produksi Hitachi di Indonesia. Secara garis besar, fokus kegiatan pada bidang usaha yang dijalankan oleh Perseroan meliputi:
a. Penjualan alat-alat besar
b. Penyewaan alat-alat besar
c. Penyediaan suku cadang
d. Dukungan pelayanan dan kontrak pemeliharaan penuh
e. Remanufaktur 
f. Pembiayaan

g. Trade-in alat alat berat

\section{Model Altman (Z-Score)}

Analisis kebangkrutan model Altman (Z-Score) digunakan untuk memprediksi kegagalan atau kebangkrutan usaha dengan melihat aspek-aspek dalam rasio keuangan, dengan membentuk persamaan diskriminan yang akan menghasilkan skor tertentu yang akan menunjukkan tingkat kemungkinan kebangkrutan perusahaan.

Penggunaan model Altman Z-Score sebagai salah satu pengukuran kinerja kebangkrutan tidak bersifat tetap ataupun stagman melainkan berkembang dari waktu ke waktu, yang mana pengujian dan penemuan model terus diperluas oleh Altman hingga dapat diterapkan pada semua perusahaan baik perusahaan manufaktur maupun perusahaan non maknufaktur khusunya perusahaan jasa (Oktarina: 2017). Altman melakukan modifikasi terhadap model prediksi kebangkrutan untuk meminimalisir efek industri karena keberadaan variabel perputaran aset yaitu dengan mengeleminasi variabel X5 (Sales to Total Assets). Dengan model yang telah modifikasi, model Altman Z-Score dapat diterapkan pada semua perusahaan baik perusahaan manufaktur dan nonmanufaktur (Altman: 2000).

Model persamaan yang digunakan untuk menghitung z-score adalah:

$Z=6,56 X 1+3,26 \times 2+6,72 X 3+1,05 X 4$

Dimana :

$Z$ = Nilai Z-Score

$\mathrm{X} 1=$ Working capital $/$ Total asset

X2 = Retained earning / Total asset

$\mathrm{X} 3=$ Earning before interest and taxes (EBIT) / Total asset

X4 $=$ Net Worth $/$ Total liabilites

Dengan kriteria penilaian sebagai berikut:

Jika perusahaan memiliki skor $Z>2,6$ diklasifikasikan sebagai perusahaan sangat sehat sehingga tidak mengalami kesulitan keuangan atau kemungkinan sangat kecil untuk terjadinya kebangkrutan.

Jika perusahaan mempunyai skor $Z$ diantara 1,1-2,6 diklasifikasikan sebagai perusahaan pada grey area atau area abu-abu yaitu perusahaan yang memiliki kesulitan keuangan, dimana kemungkinan besarnya tergantung kebijakan manajemen.

Jika perusahaan mempunyai $Z<1,1$ diklasifikasikan sebagai perusahaan yang memiliki kesulitan keuangan besar dan berpotensi bangkrut.

\section{Model Springate (S-Score)}

Model Springate (S-Score) dikembangkan pada tahun 1978 oleh Gordon L.V. Springate, metode potensi kebangkrutan ini dibuat dengan mengikuti metode Multiple Discriminant Analysis yang dikembangkan oleh Altman Z-score dalam mempotensi kebangkrutan. Springate menggunakan rasio keuangan sebagai alat untuk mengukur kebangkrutan pada suatu perusahaan. Adapun rumus yang telah ditemukan oleh Gordon L.V. Springate, dalam penelitian Sinarti dan Sembiring (2015) dengan istilah (S-score)

Model ini memiliki dasar perhitungan sebagai berikut :

$S=1,03 A+3,07 B+0,66 C+0,4 D$

Dimana:

$S=$ Nilai S-Score

$A=$ Working capital $/$ total asset

$B=$ Net profit before interest and taxes / total asset

C $=$ Net profit before taxes / current liability

$\mathrm{D}=$ Sales $/$ Total asset

Dengan kriteria penilaian sebagai berikut: 
Jika perusahaan memiliki skor $S>0,862$ diklasifikasikan sebagai perusahaan sangat sehat sehingga tidak mengalami kesulitan keuangan atau kemungkinan sangat kecil untuk terjadinya kebangkrutan.

Jika perusahaan mempunyai $S<0,862$ diklasifikasikan sebagai perusahaan yang mengalami kebangkrutan.

\section{Model Zmijiweski (X-Score)}

Analisis kebangkrutan model Zmijewski (X-Score) menggunakan analisis rasio yang mengukur kinerja, laverage, dan likuiditas suatu perusahaan untuk model prediksinya.

Model yang berhasil dikembangkan Zmijiweski yaitu:

$X=-4,3-4,5 X 1+5,7 X 2-0,004 X 3$

Dimana :

$X=$ Nilai $X$-Score

$\mathrm{X} 1=\mathrm{ROA}$ (net income after taxes / total asset) $\mathrm{X} 2=$ Leverage (total debt $/$ total asset)

X3 = Likuiditas (current asset / current liabilitas)

Zmijewski (1984) menyatakan bahwa perusahaan dianggap mengalami potensi kebangkrutan dengan kriteria penilaian sebagai berikut:

Jika perusahaan memiliki skor $\mathrm{X}<0$ diprediksi bahwa perusahaan sangat sehat sehingga tidak mengalami kesulitan keuangan.

Jika perusahaan memiliki skor $X \geq 0$ diprediksi akan mengalami kesulitan keuangan dimasa depan.

\section{Model Grover (G-Score)}

Analisis kebangkrutan model Grover merupakan model yang diciptakan dengan melakukan pendesainan dan penilaian ulang terhadap model Altman Z-Score. Model Grover terdapat ROA (Return On Asset) merupakan rasio yang menggukur laba bersih tahun yang didapat dari pemakaian aktiva. ROA yang semakin tinggi menunjukan profitasbilitas perusahaan yang membaik.

Model yang berhasil dikembangkan Grover yaitu :

G-Score $=1,650 X 1+3,404 X 2+0,016 \mathrm{ROA}+0,057$

Dimana :

X1 $=$ Working Capital $/$ Total Assets

X2 = Earnings Before Interst and Taxes (EBIT) / Total Asset

$\mathrm{ROA}=$ Net Income $/$ Total Asset

Dengan kriteria penilaian sebagai berikut:

Jika perusahaan memiliki skor $G \geq 0,01$ diprediksi bahwa perusahaan sangat sehat sehingga tidak mengalami kesulitan keuangan.

Jika perusahaan memiliki skor $\mathrm{G} \leq-0,02$ diprediksi akan mengalami kesulitan keuangan dimasa depan atau dalam keadaan bangkrut.

\section{METODE}

Dalam melakukan penelitian ini, penulis menggunakan metode kualitatif deskriptif. Penelitian kualitatif deskriptif sendiri merupakan penelitian yang bertujuan untuk mendeskripsikan, menganalisis, serta menginterprestasikan kondisi- kondisi yang terjadi untuk melihat, mengungkapkan atau menggambarkan secara tepat hal-hal yang sedang dihadapi sekarang pada perusahaan untuk menilai kinerja keuangan pada perusahaan. Objek penelitian adalah PT. Hexindo Adiperkas Tbk. Penelitian ini menggunakan data keuangan yang diperoleh dari laporan posisi keuangan dan laporan laba rugi yang disajikan dalam periode antara tahun 2016-2019. Data sekunder yang diperoleh berupa laporan tahunan dan laporan keuangan perusahaan periode 2016-2019 yang dipublikasikan di website perusahaan yaitu www.hexindo-tbk.co.id dan juga website resmi Bursa Efek Indonesia yaitu www.idx.co.id. 
HASIL DAN PEMBAHASAN

Analisis Altman Z-Score

Berdasarkan penerapan model Z-Score yang telah di lakukan pada PT. Hexindo Adiperkasa Tbk periode 2016-2019, telah diketahui masing-masing prediksi kebangkrutannya. Maka klasifikasi prediksi kebangkrutan dengan metode Altman periode 2016-2019 dapat disajikan dalam tabel berikut :

\begin{tabular}{|l|r|r|r|r|}
\hline \multicolumn{1}{|c|}{ Keterangan } & \multicolumn{1}{c|}{$\mathbf{2 0 1 9}$} & \multicolumn{1}{c|}{$\mathbf{2 0 1 8}$} & \multicolumn{1}{c|}{2017} & \multicolumn{1}{c|}{2016} \\
\hline Aktiva/Asset Lancar & 303.730 .658 & 238.267 .222 & 190.267 .668 & 230.738 .541 \\
\hline Kewajiban Lancar & 165.873 .539 & 123.157 .890 & 87.196 .752 & 43.199 .872 \\
\hline Modal Kerja (WC) & 137.857 .119 & 115.109 .332 & 103.070 .916 & 187.538 .669 \\
\hline Total Aktiva / Asset & 346.312 .450 & 283.350 .512 & 239.279 .159 & 281.604 .983 \\
\hline Laba Ditahan (RE) & 138.657 .414 & 119.096 .822 & 111.003 .741 & 198.939 .540 \\
\hline Laba Sebelum Bunga dan Pajak (EBIT) & 48.115 .002 & 30.412 .323 & 25.456 .368 & 6.362 .211 \\
\hline Ekuitas & 169.289 .200 & 150.303 .368 & 142.307 .241 & 228.715 .932 \\
\hline Total Hutang/Liabilities & 177.023 .250 & 133.047 .144 & 96.971 .918 & 52.889 .051 \\
\hline
\end{tabular}

The Z-score 2016

\begin{tabular}{|c|c|c|c|c|c|c|}
\hline \multirow{2}{*}{ Ratio Names } & \multirow{2}{*}{ Description } & \multirow{2}{*}{ Result } & \multirow[b]{2}{*}{ Coefficient } & \multirow[b]{2}{*}{ Z Score } & \multicolumn{2}{|c|}{ Mean Ratios Values Altman's Sample Cos } \\
\hline & & & & & Bankrupt & Non-Bankrupt \\
\hline \multirow[t]{2}{*}{$\mathrm{x} 1=$} & $\underline{\text { Working Capital }}$ & 0,666 & 6,56 & 4,37 & $(0,61)$ & 0,414 \\
\hline & Total Assets & & & & & \\
\hline \multirow[t]{2}{*}{$x 2=$} & Retained Earnings & 0,706 & 3,26 & 2,30 & $(0,63)$ & 0,355 \\
\hline & Total Assets & & & & & \\
\hline \multirow[t]{2}{*}{$\mathrm{x} 3=$} & $\underline{E B I T}$ & 0,023 & 6,72 & 0,15 & $(0,32)$ & 0,154 \\
\hline & Total Assets & & & & & \\
\hline \multirow[t]{3}{*}{$x 4=$} & Net Worth & 4,324 & 1,05 & 4,54 & 0,49 & 2,684 \\
\hline & Total Liabilities & & & & & \\
\hline & & & z Score & 11,36 & & \\
\hline \multicolumn{2}{|c|}{ Cut Off Values } & & & & Mean Score & \\
\hline \multicolumn{2}{|c|}{ Safe is greater than } & 2,60 & & & Non-Bankrupt & 7,70 \\
\hline \multicolumn{2}{|c|}{ Bankrupt if less than } & 1,10 & & & Bankrupt & $(4,06)$ \\
\hline
\end{tabular}

The Z-score 2017 


\begin{tabular}{|c|c|c|c|c|c|c|}
\hline \multirow{2}{*}{ Ratio Names } & \multirow{2}{*}{ Description } & \multirow{2}{*}{ Result } & \multirow[b]{2}{*}{ Coefficient } & \multirow[b]{2}{*}{ Z Score } & \multicolumn{2}{|c|}{ Mean Ratios Values Altman's Sample Cos } \\
\hline & & & & & Bankrupt & Non-Bankrupt \\
\hline \multirow[t]{2}{*}{$\mathrm{x} 1=$} & Working Capital & 0,431 & 6,56 & 2,83 & $(0,61)$ & 0,414 \\
\hline & Total Assets & & & & & \\
\hline \multirow[t]{2}{*}{$x 2=$} & Retained Earnings & 0,464 & 3,26 & 1,51 & $(0,63)$ & 0,355 \\
\hline & Total Assets & & & & & \\
\hline \multirow[t]{2}{*}{$\mathrm{x} 3=$} & $\underline{\mathrm{EBIT}}$ & 0,106 & 6,72 & 0,71 & $(0,32)$ & 0,154 \\
\hline & Total Assets & & & & & \\
\hline \multirow[t]{3}{*}{$x 4=$} & Net Worth & 1,468 & 1,05 & 1,54 & 0,49 & 2,684 \\
\hline & Total Liabilities & & & & & \\
\hline & & & Z Score & 6,59 & & \\
\hline \multicolumn{2}{|c|}{ Cut Off Values } & & & & Mean Score & \\
\hline \multicolumn{2}{|c|}{ Safe is greater than } & 2,60 & & & Non-Bankrupt & 7,70 \\
\hline \multicolumn{2}{|c|}{ Bankrupt if less than } & 1,10 & & & Bankrupt & $(4,06)$ \\
\hline
\end{tabular}

The Z-score 2018

\begin{tabular}{|c|c|c|c|c|c|c|}
\hline \multirow{2}{*}{ Ratio Names } & \multirow{2}{*}{ Description } & \multirow{2}{*}{ Result } & \multirow[b]{2}{*}{ Coefficient } & \multirow[b]{2}{*}{ Z Score } & \multicolumn{2}{|c|}{ Mean Ratios Values Altman's Sample Cos } \\
\hline & & & & & Bankrupt & Non-Bankrupt \\
\hline \multirow[t]{2}{*}{$\mathrm{x} 1=$} & Working Capital & 0,406 & 6,56 & 2,66 & $(0,61)$ & 0,414 \\
\hline & Total Assets & & & & & \\
\hline \multirow[t]{2}{*}{$\mathrm{x} 2=$} & Retained Earnings & 0,420 & 3,26 & 1,37 & $(0,63)$ & 0,355 \\
\hline & Total Assets & & & & & \\
\hline \multirow[t]{2}{*}{$\mathrm{x} 3=$} & $\underline{E B I T}$ & 0,107 & 6,72 & 0,72 & $(0,32)$ & 0,154 \\
\hline & Total Assets & & & & & \\
\hline \multirow[t]{3}{*}{$\mathrm{x} 4=$} & Net Worth & 1,130 & 1,05 & 1,19 & 0,49 & 2,684 \\
\hline & Total Liabilities & & & & & \\
\hline & & & Z Score & 5,94 & & \\
\hline \multicolumn{2}{|l|}{ Cut Off Values } & & & & Mean Score & \\
\hline \multicolumn{2}{|c|}{ Safe is greater than } & 2,60 & & & Non-Bankrupt & 7,70 \\
\hline \multicolumn{2}{|c|}{ Bankrupt if less than } & 1,10 & & & Bankrupt & $(4,06)$ \\
\hline
\end{tabular}

The Z-score 2019 


\begin{tabular}{|c|c|c|c|c|c|c|}
\hline \multirow{2}{*}{ Ratio Names } & \multirow{2}{*}{ Description } & \multirow{2}{*}{ Result } & \multirow[b]{2}{*}{ Coefficient } & \multirow[b]{2}{*}{ Z Score } & \multicolumn{2}{|c|}{ Mean Ratios Values Altman's Sample Cos } \\
\hline & & & & & Bankrupt & Non-Bankrupt \\
\hline \multirow[t]{2}{*}{$\mathrm{x} 1=$} & Working Capital & 0,398 & 6,56 & 2,61 & $(0,61)$ & 0,414 \\
\hline & Total Assets & & & & & \\
\hline \multirow[t]{2}{*}{$x 2=$} & Retained Earnings & 0,400 & 3,26 & 1,31 & $(0,63)$ & 0,355 \\
\hline & Total Assets & & & & & \\
\hline \multirow[t]{2}{*}{$\mathrm{x} 3=$} & $\underline{E B I T}$ & 0,139 & 6,72 & 0,93 & $(0,32)$ & 0,154 \\
\hline & Total Assets & & & & & \\
\hline \multirow[t]{3}{*}{$\mathrm{x} 4=$} & Net Worth & 0,956 & 1,05 & 1,00 & 0,49 & 2,684 \\
\hline & Total Liabilities & & & & & \\
\hline & & & Z Score & 5,85 & & \\
\hline \multicolumn{2}{|l|}{ Cut Off Values } & & & & Mean Score & \\
\hline \multicolumn{2}{|c|}{ Safe is greater than } & 2,60 & & & Non-Bankrupt & 7,70 \\
\hline \multicolumn{2}{|c|}{ Bankrupt if less than } & 1,10 & & & Bankrupt & $(4,06)$ \\
\hline
\end{tabular}

Dari hasil perhitungan dengan menggunakan model Altman (Z-Score) tersebut, dapat dilihat bahwa PT. Hexindo Adiperkasa, Tbk memiliki skor di atas 2,66 untuk periode tahun 2016 sampai dengan tahun 2019. Sehingga dapat disimpulkan bahwa PT. Hexindo memiliki keuangan yang sangat sehat atau tidak terdapat kesulitan keuangan yang besar dialami perusahaan yang dapat menyebabkan kebangkrutan.

\section{Analisis Springate}

Berdasarkan penerapan model Springate yang telah di lakukan pada PT. Hexindo Adiperkasa Tbk periode 2016-2019, telah diketahui masing-masing prediksi kebangkrutannya. Maka klasifikasi prediksi kebangkrutan dengan metode Springate periode 2016-2019 dapat disajikan dalam tabel berikut :

\begin{tabular}{|l|r|r|r|r|}
\hline \multicolumn{1}{|c|}{ Keterangan } & \multicolumn{1}{c|}{$\mathbf{2 0 1 9}$} & \multicolumn{1}{c|}{$\mathbf{2 0 1 8}$} & \multicolumn{1}{c|}{$\mathbf{2 0 1 7}$} & \multicolumn{1}{c|}{$\mathbf{2 0 1 6}$} \\
\hline Aktiva/Asset Lancar & \multicolumn{1}{c|}{303.730 .658} & 238.267 .222 & 190.267 .668 & 230.738 .541 \\
\hline Kewajiban Lancar & 165.873 .539 & 123.157 .890 & 87.196 .752 & 43.199 .872 \\
\hline Modal Kerja (WC) & 137.857 .119 & 115.109 .332 & 103.070 .916 & 187.538 .669 \\
\hline Total Aktiva / Asset & 346.312 .450 & 283.350 .512 & 239.279 .159 & 281.604 .983 \\
\hline Laba Ditahan (RE) & 138.657 .414 & 119.096 .822 & 111.003 .741 & 198.939 .540 \\
\hline Laba Sebelum Bunga dan Pajak (EBIT) & 48.115 .002 & 30.412 .323 & 25.456 .368 & 6.362 .211 \\
\hline Ekuitas & 169.289 .200 & 150.303 .368 & 142.307 .241 & 228.715 .932 \\
\hline Total Hutang/Liabilities & 177.023 .250 & 133.047 .144 & 96.971 .918 & 52.889 .051 \\
\hline Laba Sebelum Bunga (EBT) & 50.181 .143 & 30.627 .218 & 24.729 .412 & 10.488 .865 \\
\hline Penghasilan Netto & 463.870 .941 & 345.148 .892 & 303.878 .576 & 275.437 .463 \\
\hline
\end{tabular}


SPRINGATE 2016

\begin{tabular}{|c|c|c|c|c|}
\hline Ratio Names & Description & Result & Coefficient & Springate \\
\hline \multirow[t]{2}{*}{$A=$} & Working Capital & 0,666 & 1,03 & 0,69 \\
\hline & Total Assets & & & \\
\hline \multirow[t]{2}{*}{$B=$} & EBIT & 0,023 & 3,07 & 0,07 \\
\hline & Total Assets & & & \\
\hline \multirow[t]{2}{*}{$C=$} & EBT & 0,243 & 0,66 & 0,16 \\
\hline & Current Liabilities & & & \\
\hline \multirow[t]{6}{*}{$D=$} & Sales & 0,978 & 0,4 & 0,39 \\
\hline & Total Assets & & & \\
\hline & & & Springate & 1,31 \\
\hline & Mean Score & & & \\
\hline & Non-Bankrupt & $S>0,862$ & & \\
\hline & Bankrupt & $S<0,862$ & & \\
\hline
\end{tabular}

\section{SPRINGATE 2017}

\begin{tabular}{|c|c|c|c|c|}
\hline Ratio Names & Description & Result & Coefficient & Springate \\
\hline \multirow[t]{2}{*}{$A=$} & Working Capital & 0,431 & 1,03 & 0,44 \\
\hline & Total Assets & & & \\
\hline \multirow[t]{2}{*}{$B=$} & EBIT & 0,106 & 3,07 & 0,33 \\
\hline & Total Assets & & & \\
\hline \multirow[t]{2}{*}{$C=$} & $\underline{E B T}$ & 0,284 & 0,66 & 0,19 \\
\hline & Current Liabilities & & & \\
\hline \multirow[t]{6}{*}{$D=$} & Sales & 1,270 & 0,4 & 0,51 \\
\hline & Total Assets & & & \\
\hline & & & Springate & 1,47 \\
\hline & Mean Score & & & \\
\hline & Non-Bankrupt & $S>0,862$ & & \\
\hline & Bankrupt & $S<0,862$ & & \\
\hline
\end{tabular}




\begin{tabular}{|c|c|c|c|c|}
\hline \multicolumn{2}{|c|}{ SPRINGATE 2018} & \multirow[b]{2}{*}{ Result } & \multirow[b]{2}{*}{ Coefficient } & \multirow[b]{2}{*}{ Springate } \\
\hline Ratio Names & Description & & & \\
\hline \multirow[t]{2}{*}{$A=$} & Working Capital & 0,406 & 1,03 & 0,42 \\
\hline & Total Assets & & & \\
\hline \multirow[t]{2}{*}{$B=$} & $\underline{\text { EBIT }}$ & 0,107 & 3,07 & 0,33 \\
\hline & Total Assets & & & \\
\hline \multirow[t]{2}{*}{$C=$} & $\underline{E B T}$ & 0,249 & 0,66 & 0,16 \\
\hline & Current Liabilities & & & \\
\hline \multirow[t]{6}{*}{$D=$} & Sales & 1,218 & 0,4 & 0,49 \\
\hline & Total Assets & & & \\
\hline & & & Springate & 1,40 \\
\hline & Mean Score & & & \\
\hline & Non-Bankrupt & $S>0,862$ & & \\
\hline & Bankrupt & $S<0,862$ & & \\
\hline
\end{tabular}

\begin{tabular}{|c|c|c|c|c|}
\hline \multicolumn{2}{|c|}{ SPRINGATE 2019} & \multirow[b]{2}{*}{ Result } & \multirow[b]{2}{*}{ Coefficient } & \multirow[b]{2}{*}{ Springate } \\
\hline Ratio Names & Description & & & \\
\hline \multirow[t]{2}{*}{$A=$} & Working Capital & 0,398 & 1,03 & 0,41 \\
\hline & Total Assets & & & \\
\hline \multirow[t]{2}{*}{$B=$} & $\underline{E B I T}$ & 0,139 & 3,07 & 0,43 \\
\hline & Total Assets & & & \\
\hline \multirow[t]{2}{*}{$C=$} & $\underline{E B T}$ & 0,303 & 0,66 & 0,20 \\
\hline & Current Liabilities & & & \\
\hline \multirow[t]{6}{*}{$D=$} & $\underline{\text { Sales }}$ & 1,339 & 0,4 & 0,54 \\
\hline & Total Assets & & & \\
\hline & & & Springate & 1,57 \\
\hline & Mean Score & & & \\
\hline & Non-Bankrupt & $S>0,862$ & & \\
\hline & Bankrupt & $S<0,862$ & & \\
\hline
\end{tabular}

Dari hasil perhitungan dengan menggunakan model Springate (S-score) tersebut, dapat dilihat bahwa PT. Hexindo Adiperkasa, Tbk memiliki skor di atas 0,862 untuk periode tahun 2016 hingga 2019. Sehingga dapat disimpulkan bahwa PT. Hexindo memiliki keuangan yang sangat sehat atau tidak terdapat kesulitan keuangan yang besar dialami perusahaan yang dapat menyebabkan kebangkrutan.

\section{Analisis Zmijweski}

Berdasarkan penerapan model Zmijweski yang telah di lakukan pada PT. Hexindo Adiperkasa Tbk periode 2016-2019, telah diketahui masing-masing prediksi 
kebangkrutannya. Maka klasifikasi prediksi kebangkrutan dengan metode Zmijweski periode 2016-2019 dapat disajikan dalam tabel berikut :

\begin{tabular}{|l|r|r|r|r|}
\hline \multicolumn{1}{|c|}{ Keterangan } & \multicolumn{1}{c|}{$\mathbf{1}$ 2019 } & \multicolumn{1}{c|}{2018} & \multicolumn{1}{c|}{$\mathbf{2 0 1 7}$} & \multicolumn{1}{c|}{2016} \\
\hline Aktiva/Asset Lancar & 303.730 .658 & 238.267 .222 & 190.267 .668 & 230.738 .541 \\
\hline Kewajiban Lancar & 165.873 .539 & 123.157 .890 & 87.196 .752 & 43.199 .872 \\
\hline Modal Kerja (WC) & 137.857 .119 & 115.109 .332 & 103.070 .916 & 187.538 .669 \\
\hline Total Aktiva / Asset & 346.312 .450 & 283.350 .512 & 239.279 .159 & 281.604 .983 \\
\hline Laba Ditahan (RE) & 138.657 .414 & 119.096 .822 & 111.003 .741 & 198.939 .540 \\
\hline Laba Sebelum Bunga dan Pajak (EBIT) & 48.115 .002 & 30.412 .323 & 25.456 .368 & 6.362 .211 \\
\hline Ekuitas & 169.289 .200 & 150.303 .368 & 142.307 .241 & 228.715 .932 \\
\hline Total Hutang/Liabilities & 177.023 .250 & 133.047 .144 & 96.971 .918 & 52.889 .051 \\
\hline Laba Sebelum Bunga (EBT) & 50.181 .143 & 30.627 .218 & 24.729 .412 & 10.488 .865 \\
\hline Penghasilan Netto & 463.870 .941 & 345.148 .892 & 303.878 .576 & 275.437 .463 \\
\hline Laba Bersih setelah pajak & 37.600 .177 & 22.549 .481 & 18.072 .201 & 7.514 .289 \\
\hline
\end{tabular}

ZMIJWESKI 2016

\begin{tabular}{|c|c|c|c|c|}
\hline Ratio Names & Description & Result & Coefficient & ZMIJWESKI \\
\hline & & & $(4,3)$ & \\
\hline \multirow[t]{2}{*}{$\mathrm{X} 1=\mathrm{ROA}$} & Net income after taxes & 0,027 & 4,5 & 0,12 \\
\hline & Total Assets & & & \\
\hline \multirow[t]{2}{*}{$\mathrm{X} 2$ = Leverage } & $\underline{\text { Total Debt }}$ & 0,188 & 5,7 & 1,07 \\
\hline & Total Assets & & & \\
\hline \multirow[t]{6}{*}{$\mathrm{X} 3=$ Likuiditas } & Current assets & 5,341 & 0,004 & 0,02 \\
\hline & Current Liabilities & & & \\
\hline & & & ZMIJWESKI & $(3,37)$ \\
\hline & Mean Score & & & \\
\hline & Non-Bankrupt & $x<0$ & & \\
\hline & Bankrupt & $x \geq 0$ & & \\
\hline
\end{tabular}




\begin{tabular}{|c|c|c|c|c|}
\hline \multicolumn{5}{|c|}{ ZMIJWESKI 2017} \\
\hline Ratio Names & Description & Result & Coefficient & ZMIJWESKI \\
\hline & & & $(4,3)$ & \\
\hline \multirow[t]{2}{*}{$\mathrm{X} 1=\mathrm{ROA}$} & Net income after taxes & 0,076 & 4,5 & 0,34 \\
\hline & Total Assets & & & \\
\hline \multirow[t]{2}{*}{$\mathrm{X} 2$ = Leverage } & Total Debt & 0,405 & 5,7 & 2,31 \\
\hline & Total Assets & & & \\
\hline \multirow[t]{6}{*}{ X3= Likuiditas } & Current assets & 2,182 & 0,004 & 0,01 \\
\hline & Current Liabilities & & & \\
\hline & & & ZMIJWESKI & $(2,34)$ \\
\hline & Mean Score & & & \\
\hline & Non-Bankrupt & $x<0$ & & \\
\hline & Bankrupt & $x \geq 0$ & & \\
\hline
\end{tabular}

ZMIJWESKI 2018

\begin{tabular}{|c|c|c|c|c|}
\hline Ratio Names & Description & Result & Coefficient & ZMIJWESKI \\
\hline & & & $(4,3)$ & \\
\hline \multirow[t]{2}{*}{$\mathrm{X} 1=\mathrm{ROA}$} & Net income after taxes & 0,080 & 4,5 & 0,36 \\
\hline & Total Assets & & & \\
\hline \multirow[t]{2}{*}{$\mathrm{X} 2$ = Leverage } & $\underline{\text { Total Debt }}$ & 0,470 & 5,7 & 2,68 \\
\hline & Total Assets & & & \\
\hline \multirow[t]{6}{*}{ X3= Likuiditas } & Current assets & 1,935 & 0,004 & 0,01 \\
\hline & Current Liabilities & & & \\
\hline & & & ZMIJWESKI & $(1,99)$ \\
\hline & Mean Score & & & \\
\hline & Non-Bankrupt & $x<0$ & & \\
\hline & Bankrupt & $x \geq 0$ & & \\
\hline
\end{tabular}


ZMIJWESKI 2019

\begin{tabular}{|c|c|c|c|c|}
\hline Ratio Names & Description & Result & Coefficient & ZMIJWESKI \\
\hline & & & $(4,3)$ & \\
\hline \multirow[t]{2}{*}{$\mathrm{X} 1=\mathrm{ROA}$} & Net income after taxes & 0,109 & 4,5 & 0,49 \\
\hline & Total Assets & & & \\
\hline \multirow[t]{2}{*}{$\mathrm{X} 2$ = Leverage } & Total Debt & 0,511 & 5,7 & 2,91 \\
\hline & Total Assets & & & \\
\hline \multirow[t]{6}{*}{ X3= Likuiditas } & Current assets & 1,831 & 0,004 & 0,01 \\
\hline & Current Liabilities & & & \\
\hline & & & ZMIJWESKI & $(1,88)$ \\
\hline & Mean Score & & & \\
\hline & Non-Bankrupt & $x<0$ & & \\
\hline & Bankrupt & $x \geq 0$ & & \\
\hline
\end{tabular}

Dari hasil perhitungan dengan menggunakan rumus model Zmijewski ((X-Score) tersebut, dapat dilihat bahwa PT. Hexindo Adiperkasa, Tbk memiliki skor di bawah 0 untuk periode tahun 2016 hingga 2019. Sehingga dapat disimpulkan bahwa PT. Hexindo memiliki keuangan yang sangat sehat atau tidak terdapat kesulitan keuangan yang besar dialami perusahaan yang dapat menyebabkan kebangkrutan.

Dari hasil perhitungan dengan menggunakan rumus model Zmijewski (X-Score) tersebut, dapat dilihat bahwa PT. Hexindo Adiperkasa, Tbk memiliki skor di bawah 0 untuk periode tahun 2016 hingga 2019. Sehingga dapat disimpulkan bahwa PT. Hexindo memiliki keuangan yang sangat sehat atau tidak terdapat kesulitan keuangan yang besar dialami perusahaan yang dapat menyebabkan kebangkrutan.

\section{Analisis Grover}

Berdasarkan penerapan model Grover yang telah di lakukan pada PT. Hexindo Adiperkasa Tbk periode 2016-2019, telah diketahui masing-masing prediksi kebangkrutannya. Maka klasifikasi prediksi kebangkrutan dengan metode Grover periode 2016-2019 dapat disajikan dalam tabel berikut :

\begin{tabular}{|l|r|r|r|r|}
\hline \multicolumn{1}{|c|}{ Keterangan } & \multicolumn{1}{c|}{2019} & \multicolumn{1}{c|}{2018} & \multicolumn{1}{c|}{2017} & \multicolumn{1}{c|}{2016} \\
\hline Aktiva/Asset Lancar & 303.730 .658 & 238.267 .222 & 190.267 .668 & 230.738 .541 \\
\hline Kewajiban Lancar & 165.873 .539 & 123.157 .890 & 87.196 .752 & 43.199 .872 \\
\hline Modal Kerja (WC) & 137.857 .119 & 115.109 .332 & 103.070 .916 & 187.538 .669 \\
\hline Total Aktiva / Asset & 346.312 .450 & 283.350 .512 & 239.279 .159 & 281.604 .983 \\
\hline Laba Ditahan (RE) & 138.657 .414 & 119.096 .822 & 111.003 .741 & 198.939 .540 \\
\hline Laba Sebelum Bunga dan Pajak (EBIT) & 48.115 .002 & 30.412 .323 & 25.456 .368 & 6.362 .211 \\
\hline Ekuitas & 169.289 .200 & 150.303 .368 & 142.307 .241 & 228.715 .932 \\
\hline Total Hutang/Liabilities & 177.023 .250 & 133.047 .144 & 96.971 .918 & 52.889 .051 \\
\hline Laba Sebelum Bunga (EBT) & 50.181 .143 & 30.627 .218 & 24.729 .412 & 10.488 .865 \\
\hline Penghasilan Netto & 463.870 .941 & 345.148 .892 & 303.878 .576 & 275.437 .463 \\
\hline Laba Bersih setelah pajak & 37.600 .177 & 22.549 .481 & 18.072 .201 & 7.514 .289 \\
\hline
\end{tabular}




\begin{tabular}{|c|c|c|c|c|}
\hline Grover 2016 & & & & \\
\hline Ratio Names & Description & Result & Coefficient & Grover \\
\hline \multirow[t]{2}{*}{$\mathrm{x} 1=$} & Working Capital & 0,666 & 1,650 & 1,10 \\
\hline & Total Assets & & & \\
\hline \multirow[t]{2}{*}{$x 2=$} & EBIT & 0,023 & 3,404 & 0,08 \\
\hline & Total Assets & & & \\
\hline \multirow[t]{8}{*}{$\mathrm{ROA}=$} & Net Income & 0,027 & 0,016 & 0,00 \\
\hline & $\overline{\text { Total Assets }}$ & & & \\
\hline & & & & \\
\hline & & & 0,057 & \\
\hline & & & Grover & 1,23 \\
\hline & Mean Score & & & \\
\hline & Non-Bankrupt & Score $\geq 0,01$ & & \\
\hline & Bankrupt & Score $\leq-0,02$ & & \\
\hline
\end{tabular}

Grover 2017

\begin{tabular}{|l|c|c|c|c|}
\hline Ratio Names & Description & Result & Coefficient & Grover \\
\hline $\mathrm{X} 1=$ & Working Capital & 0,431 & 1,650 & 0,71 \\
\hline $\mathrm{X} 2=$ & EBIT & 0,106 & 3,404 & 0,36 \\
\hline ROA $=$ & Total Assets & 0,076 & 0,016 & 0,00 \\
\hline & Net Income & & & \\
\hline & Total Assets & & 0,057 & $\mathbf{1 , 1 3}$ \\
\hline & & & Grover & \\
\hline & Mean Score & Score $\geq \mathbf{0 , 0 1}$ & & \\
\hline & Non-Bankrupt & & & \\
\hline & Bankrupt & & & \\
\hline
\end{tabular}




\begin{tabular}{|c|c|c|c|c|}
\hline Grover 2018 & & & & \\
\hline Ratio Names & Description & Result & Coefficient & Grover \\
\hline \multirow[t]{2}{*}{$\mathrm{x} 1=$} & Working Capital & 0,406 & 1,650 & 0,67 \\
\hline & Total Assets & & & \\
\hline \multirow[t]{2}{*}{$x 2=$} & $\underline{E B I T}$ & 0,107 & 3,404 & 0,37 \\
\hline & Total Assets & & & \\
\hline \multirow[t]{9}{*}{$\mathrm{ROA}=$} & Net Income & 0,080 & 0,016 & 0,00 \\
\hline & Total Assets & & & \\
\hline & & & & \\
\hline & & & 0,057 & \\
\hline & & & Grover & 1,09 \\
\hline & & & & \\
\hline & Mean Score & & & \\
\hline & Non-Bankrupt & Score $\geq 0,01$ & & \\
\hline & Bankrupt & Score $\leq-0,02$ & & \\
\hline
\end{tabular}

\begin{tabular}{|c|c|c|c|c|}
\hline \multicolumn{5}{|l|}{ Grover 2019} \\
\hline Ratio Names & Description & Result & Coefficient & Grover \\
\hline \multirow[t]{2}{*}{$\mathrm{x} 1=$} & Working Capital & 0,398 & 1,650 & 0,66 \\
\hline & Total Assets & & & \\
\hline \multirow[t]{2}{*}{$\times 2=$} & EBIT & 0,139 & 3,404 & 0,47 \\
\hline & Total Assets & & & \\
\hline \multirow[t]{7}{*}{$\mathrm{ROA}=$} & Net Income & 0,109 & 0,016 & 0,00 \\
\hline & Total Assets & & & \\
\hline & & & 0,057 & \\
\hline & & & Grover & 1,19 \\
\hline & Mean Score & & & \\
\hline & Non-Bankrupt & Score $\geq 0,01$ & & \\
\hline & Bankrupt & Score $\leq-0,02$ & & \\
\hline
\end{tabular}

Dari hasil perhitungan dengan menggunakan rumus model Grover (G-Score) tersebut, dapat dilihat bahwa PT. Hexindo Adiperkasa, Tbk memiliki skor di atas 0,01 untuk periode tahun 2016 hingga 2019. Sehingga dapat disimpulkan bahwa PT. Hexindo memiliki keuangan yang sangat sehat atau tidak terdapat kesulitan keuangan yang besar dialami perusahaan yang dapat menyebabkan kebangkrutan. 


\section{Analisis Potensi Kebangkrutan PT. Hexindo Adiperkasa, Tbk}

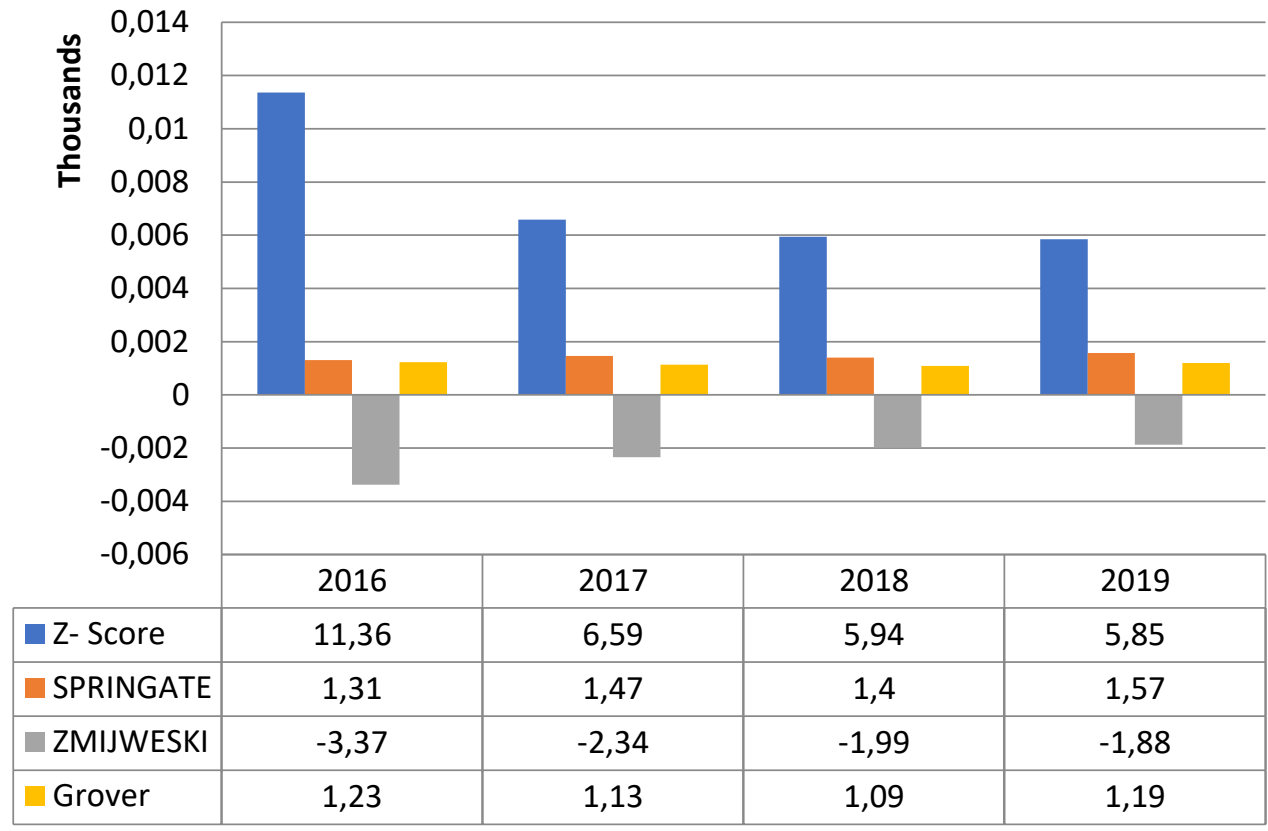

Grafik Analisis Kebangkrutan PT. Hexindo Adiperkasa periode tahu 2016 -2019

Berdasarkan hasil analisis potensi kebangkrutan dengan model Z-Score, Springate, Zmijewski, dan Grover pada PT. Hexindo Adiperkasa, Tbk periode 2016-2019 yang telah diketahui prediksi kebangkrutan dari masing-masing model, maka dapat dirangkum dalam tabel berikut :

\begin{tabular}{|l|l|l|}
\hline Uji & Hasil Rata-Rata & Tafsiran \\
\hline Altman z score & 7,43 & Sehat \\
\hline Springate & 1,43 & Sehat \\
\hline Zmijewski & $(2,39)$ & Sehat \\
\hline Grover & 1,16 & Sehat \\
\hline
\end{tabular}

Tabel Rangkuman Hasil Rata-Rata Uji Penelitian Metode Z-Score, Springate, Zmijewski, Grover 2016-2019

Berdasarkan rangkuman hasil rata-rata uji penelitian metode Z-Score, Springate, Zmijewski, dan Grover, hasil uji menyatakan bahwa PT. Hexindo Adiperkasa, Tbk periode 2016-2019 diindikasikan dalam kondisi tidak bangkrut atau sehat, dan kecil kemungkinan untuk mengalami kebangkrutan.

\section{SIMPULAN}

Dari hasil analisis potensi kebangkrutan dengan menggunakan metode Altman ZScore, Springate, ZMIJEWSKI dan Grover dapat disimpulkan bahwa PT. Hexindo Adiperkasa, Tbk tidak mengalami adanya suatu potensi kebangkrutan disini menunjukan bahwa perusahaan dalam kondisi sehat. Namun walaupun dalam kondisi sehat kita dapat melihat pada grafik bahwa terjadinya penurunan disetiap tahunnya. Disini dibutuhkan agar pihak manajemen dapat memperhatikan dan meningkatkan kinerja keuangan perusahaan agar terhindar dari kebangkrutan 


\section{DAFTAR PUSTAKA}

Azmi, Z., Nasution, A.A., \& Muda, I. (2020). Information System Integration, Knowledge Management, and Management Accounting Adaptibility, ICOSTEER 2018 research in industry 4, 1887-1894

Astuti, M., Azmi, Z., Darwin, R., 2020. Pengaruh Competitor Accounting Terhadap Keunggulan Bersaing dan Kinerja Organisasi, Research in Accounting Journal (RAJ) $1(1), 1-15$

Hafiz Adnan \& Dicky Arisudhana, (2012) Analisis Kebangkrutan Model Altman Z-Score dan Springate pada perusahaan Industri Property, Jurnal Akuntansi dan Keuangan, Vol 1, No 1.

Kusuma, H. 2006. Manajemen Produksi : Perencanaan dan Pengendalian Produksi. BPFE, Yogyakarta

Lubis, P.I.A., Azmi, Z., Suriyanti, L.H., 2020. Pengaruh Customer Accounting Dan Customer Orientation Terhadap Kinerja Organisasi, Jurnal Al-lqtishad, 15 (2), 180-215

Munawir. (2010). Analisa Laporan Keuangan. Yogyakarta: Liberty.

Oktarina, Eka. (2017). “Analisis Prediksi Kebangkrutan Dengan Metode Altman Z-Score Pada PT. BRI Syariah". Skripi Tidak Dipublikasikan. Universitas Islam Negeri Raden Fatah Palembang. Sumatera Selatan

Restuti, Maria Immaculatta Mitha Dwi, 2006, Pengaruh Pertumbuhan Perusahaan Terhadap Peringkat Dan Yield Obligasi.

Rismawati. 2012. Analisis Perbandingan Model Prediksi Financial Distress Altman, Springate, Ohlson, Dan Zmijewski (Studi empiris pada Perusahaan Manufaktur yang Terdaftar di Bursa Efek Indonesia. (Skripsi). Fakultas Ekonomi dan Bisnis Universitas Hasanuddin.

Sinarti and Sembiring. 2015. Bankruptcy Prediction Analysis of Manufacturing Companies Listed in Indonesia Stock Exchange. Internasional Jounal of Economics and Financial Issues, Vol 5:354-359.ISSN: 2146-4138.

Zmijewski, M.E. 1984. Methodological Issues Related to The Estimation of Finansial Distress Prediction Model. Jurnal of Accounting Research 24 (supplement).

https://www.hexindo-tbk.co.id/wp-content/uploads/2017/03/Hexa_Lap.Keu_.Tahunan2016.pdf

https://www.hexindo-tbk.co.id/wp-content/uploads/2019/07/HexindoAdiperkasa Bilingual 31 Maret 2019.pdf 